\title{
EL DESFAVORECIMIENTO RURAL: UNA PROPUESTA PARA SU MEDICIÓN APLICADAA LA REALIDAD TERRITORIAL DE CASTILLA-LA MANCHA
}

\author{
Óscar Serrano Gil \\ Ana Eulalia Aparicio Guerrero \\ Departamento de Geografía y Ordenación del Territorio. Universidad de Castilla-La Mancha \\ Oscar.Serrano@uclm.es, Ana.Aparicio@uclm.es
}

\section{RESUMEN}

El mundo rural presenta una realidad variada y cargada de contrastes, con situaciones económicas, demográficas, sociales, territoriales y de desarrollo heterogéneas y muy dispares entre sí. Nuestra investigación presenta una herramienta metodológica para el análisis del desfavorecimiento rural en el territorio de Castilla-La Mancha utilizando un conjunto de indicadores agrupados en tres categorías: criterios demográficos, criterios derivados de la relación de la población con la actividad económica y criterios vinculados a las características del parque residencial. El establecimiento de un índice de desfavorecimiento para cada uno de los municipios rurales de la región nos lleva a identificar la existencia de una clara dicotomía socioeconómica en el territorio analizado.

Palabras clave: desfavorecimiento rural, Castilla-La Mancha, demografía, indicador, actividades económicas.

\section{ABSTRACT}

The rural world presents a varied and charged reality of contrasts with demographic, economic, social, territorial situations and a heterogeneous development together. Our research shows a methodological tool for the analysis of the rural disadvantage in the territory of Castilla-La Mancha. For that, it has used a set of indicators grouped into three categories: demographic, criteria from the relationship between people and the economic

Fecha de recepción: mayo 2016.

Fecha de aceptación: julio 2017. 
activity and measures linked to the housing characteristics. The establishment of an index of disadvantage for each of the rural municipalities of the region leads us to identifying the existence of a clear socioeconomic dichotomy in the analyzed territory.

Key words: rural disadvantage, Castilla-La Mancha, demography, indicator, activity economic.

\section{INTRODUCCIÓN}

En las últimas décadas, los temas relacionados con la calidad medioambiental, el acceso a los recursos, el bienestar y las desigualdades, han ocupado una parte importante de la investigación en geografía humana. Algunos autores han considerado el estudio de los aspectos espaciales del bienestar humano como uno de los objetivos fundamentales de esta disciplina. Este interés, enmarcado en un sentimiento generalizado de frustración ante la inexistencia de actuaciones destinadas a poner el desarrollo tecnológico al servicio de la superación de los desequilibrios socioeconómicos, de situaciones injustas en el mundo y del progresivo deterioro ambiental, se ha concretado en varios trabajos geográficos que plantean estas temáticas a distintas escalas (Coates, Johnston y Knox, 1977; Cox, 1979; Smith, 1977, 1979). Sin embargo, la mayor parte de los estudios realizados se centran en la escala urbana, debido a dos razones fundamentales: el notable crecimiento de la población urbana en el mundo occidental durante las pasadas décadas, y el hecho de que las desigualdades y los problemas sociales se muestran más agudamente en las urbes.

En este contexto y desde el ámbito de trabajo de la geografía urbana, el concepto de desfavorecimiento se ha aplicado mayoritariamente al análisis a gran escala de barrios urbanos desfavorecidos desde una perspectiva compleja debido a la combinación intrínseca de dos aspectos. El primero está vinculado con el ámbito de lo territorial, mientras que el segundo está relacionado con lo social y conductual, llegando a la conclusión de que las situaciones de exclusión social se concentran en determinadas áreas urbanas (Room, 1995). La razón es que estas zonas desfavorecidas presentan unos atributos de base espacial poco atractivos para la sociedad -y por lo tanto para el mercado inmobiliario- en comparación con la calidad de otros barrios urbanos. Además, las características socioeconómicas de la población se convierten en un buen indicador de las condiciones del barrio si se asume que la distribución de los grupos sociales dentro del espacio urbano se produce a partir de mecanismos de segmentación por renta mediante los cuales estos grupos, en función de sus recursos y sus posibilidades, acceden a mayores o menores niveles de calidad de la vivienda en distintos sectores de la ciudad. Existen varios indicadores de carácter básico que sirven para medir estas variables socioeconómicas de la población residente en un área, que generalmente responden a índices relacionados con el desempleo, el nivel educativo y formativo de la población, y/o la renta de las familias. El resultado de la falta de atractivo de los barrios desfavorecidos es la concentración espacial de familias con menos recursos económicos y menos oportunidades de elección en cuanto a la localización residencial se refiere siendo, por tanto, más vulnerables de cara a la exclusión social (Murie y Musterd, 2004). A estos factores se une el precio de la vivienda en el mercado 
inmobiliario, notablemente inferior en estas zonas frente a otras áreas de la ciudad, tanto en alquiler como en venta, lo que opera como un factor selectivo y de atracción de un determinado grupo social que no puede acceder a mayores niveles de gasto en cuestión residencial (Bruquetas, Moreno y Walliser, 2005).

El análisis del desfavorecimiento, utilizando índices estandarizados aplicado a espacios rurales, ha sido mucho menos frecuente entre la investigación académica vinculada tanto al campo de la geografía como de la sociología, al menos en el caso español. Las aportaciones más interesantes proceden del mundo anglosajón donde se encuentran contribuciones de indudable relevancia desde la década de los años ochenta del pasado siglo (Cullingford y Openshaw, 1982; Dunn, Hodge, Monk y Kiddle, 1998; Martin, Brigham y Roderick, 2000; McLauglin, 1986; Shucksmith, 2000). Los procesos de despoblamiento -dominantes en la mayor parte de zonas rurales hasta fechas recientes- han ocasionado un deterioro en los servicios y en las condiciones de vida; una pérdida de servicios escolares, sanitarios, culturales, sociales y comerciales; una falta de dotaciones y de inversiones en infraestructuras; una decadencia e incluso desaparición de los transportes públicos; y una sociedad envejecida, con bajas rentas económicas y elevada proporción de jubilados. A ello se añadiría la cuestión de la accesibilidad (Moseley, 1979) fundamental para entender los problemas derivados del aislamiento, de las bajas densidades de población y de los sistemas deficientes de transportes, que en muchos casos son la base fundamental de la cohesión territorial. Ya algunos trabajos (Knox y Cottam, 1981; Philips y Williams, 1984) bajo el epígrafe del empobrecimiento y deterioro del medio rural (“deprivation") señalan como principales componentes del mismo las condiciones de la vivienda, las dificultades de acceso a servicios tales como la enseñanza y las restricciones de movilidad. No hay que olvidar que la realidad del mundo rural es muy variada y caracterizada por notables contrastes entre los territorios. Clout (1993) y Nogués (2004) han reflexionado sobre las enormes diferencias para poder caracterizar y clasificar las áreas rurales apelando a diversos criterios como la baja densidad de población, la escasa dotación de infraestructuras y el dominio de los usos del suelo agrícola o silvícola.

Las áreas rurales españolas, y por supuesto las de Castilla-La Mancha, como el resto de las europeas en general, se caracterizan por una notable diferenciación (CuadradoRoura, Yserte y Mancha, 1999) que proporciona un excepcional abanico de situaciones, abarcando desde las áreas rurales periurbanas, plenamente integradas en los procesos de desarrollo y vinculadas de forma directa e inmediata a los impulsos urbanos, hasta los sectores rurales residuales con una escasa población, con elevadas tasas de envejecimiento, un alto grado de desestructuración social y un claro perfil agrario de pura subsistencia. Entre ambos extremos existe un conjunto de situaciones heterogéneas, con una distribución regional y local diferenciada, que presentan índices económicos, demográficos, sociales, de integración territorial y de desarrollo muy dispares entre sí.

En cualquier caso, el desarrollo rural, nacido al amparo de las nuevas potencialidades de estos espacios ante la crisis del mundo rural y especialmente de las actividades agrícolas y ganaderas, se ha erigido en el principal motor de acción para los espacios más desfavorecidos, que han pasado del agrarismo propio de algunas comarcas naturales a la apuesta por las medidas de desarrollo rural (Pillet Capdepón, 2001) con la introducción, de un tiempo a esta parte, de nuevas inversiones y mejoras (Gozálvez Pérez, 2001). 
Ahora bien, el impulso rural ha conseguido, mediante el conjunto de medidas, planes y programas asociados, un sólido desarrollo en algunas comarcas y municipios de la región debido a la buena gestión administrativa, financiera y empresarial, pero no ha sido el revulsivo fulminante para la salida del atraso de otras comarcas desfavorecidas, como la Sierra de Ayllón, la Sierra de Alcaraz, Los Montes de Toledo o la Serranía de Cuenca.

\section{OBJETIVOS, METODOLOGÍA Y FUENTES}

Partiendo de este contexto, el objetivo fundamental de nuestra investigación es delimitar territorios rurales homogéneos a partir del cálculo de un Índice de Desfavorecimiento Rural (IDR) basado en un conjunto de indicadores socioeconómicos a escala municipal en el medio rural castellano-manchego.

Para ello, apoyándonos en la propuesta metodológica del profesor Valenzuela Rubio (2008), en el marco del proyecto denominado Puesta en valor sostenible de las estructuras rurales para el turismo y el ocio de las poblaciones rurales (TERRITURAL), se ha seleccionado un elenco de variables agrupadas en tres criterios básicos: criterios demográficos, criterios derivados de la relación de la población con la actividad económica y criterios vinculados a las características del parque residencial (Tabla 1). En la metodología propuesta se recogen diez indicadores para el cálculo de un índice aplicado a escala comarcal. En nuestro caso, a los indicadores utilizados en ese trabajo se han sumado la población extranjera, la población activa, los afiliados a la Seguridad Social y las empresas dadas de alta en este sistema de protección social, descendiendo el nivel de estudio a escala municipal. Para baremar los indicadores les hemos otorgado una ponderación entre 0 y 10 con el fin de generar un índice integrado compuesto por las catorce variables numéricas, de forma que al sumar sus valores obtendremos un índice que variará entre 1 y 140, valores mínimo y máximo de desfavorecimiento rural.

En el cálculo se han encontrado algunas dificultades relacionadas con el acceso y la calidad de la información disponible. Obviamente, y dado que se trata de datos estandarizados, se ha recurrido a diversas fuentes indirectas, como las estadísticas de la Seguridad Social referidas a situaciones de alta laboral de trabajadores, y a la revisión del Padrón municipal de habitantes para los datos de carácter demográfico. En el caso del Censo de Población y Vivienda del 2011 los inconvenientes derivan de las características del documento, que más que un censo propiamente dicho es el resultado de la combinación de los siguientes elementos: (1) un fichero precensal realizado a partir de los registros administrativos disponibles, tomando al Padrón como elemento básico de su estructura; y (2) un trabajo de campo que incluye dos operaciones, un Censo de Edificios exhaustivo que permite la georreferenciación de todos los edificios, y una encuesta por muestreo para conocer las características de las personas y las viviendas.

Con el fin de homologar el conjunto de variables, la mayoría se han calculado referidas al año 2015. No obstante, en algunas ocasiones, en aquellos casos puntuales en que ha sido imposible localizar y trabajar con una fuente fiable en ese año, se ha tenido que recurrir al censo de 2011, y ante las carencias del mismo, se ha optado por utilizar los datos del censo anterior (año 2001). Hay que tener en cuenta que cuando las fuentes estadísticas ofrecen 
información para municipios que superan los 2.000 habitantes se prescinde de más del 75\% de los municipios de Castilla-La Mancha y cuando el umbral se sitúa en los 10.000 habitantes, caso del censo de 2011, queda excluido el $96 \%$ de los municipios castellano-manchegos ${ }^{1}$.

Tabla 1

INDICADORES BÁSICOS PARA EL CÁLCULO DEL ÍNDICE DE DESFAVORECIMIENTO

\begin{tabular}{|c|c|c|c|}
\hline & & Año & Fuente $^{2}$ \\
\hline \multicolumn{4}{|c|}{ Criterios demográficos } \\
\hline \multirow{5}{*}{ 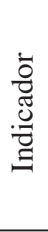 } & Evolución de la población & 2001-2015 & INE \\
\hline & Envejecimiento de la población & 2015 & INE \\
\hline & Reemplazo & 2015 & INE \\
\hline & Nivel formativo (secundaria) & 2001 & INE \\
\hline & Población extranjera & 2015 & IESCLM \\
\hline \multicolumn{4}{|c|}{ Criterios derivados de la relación de la población con la actividad económica } \\
\hline \multirow{6}{*}{ 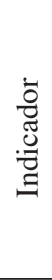 } & Población activa & 2015 & MESS \\
\hline & Afiliados a la Seguridad Social & 2015 & MESS \\
\hline & Paro & 2015 & IESCLM \\
\hline & Empresas dadas de alta en la Seguridad Social & 2015 & IESCLM \\
\hline & Población vinculada y no residente & 2001 & INE \\
\hline & Sectores económicos & 2015 & IESCLM \\
\hline \multicolumn{4}{|c|}{ Criterios vinculados a las características del parque residencial } \\
\hline \multirow{3}{*}{ 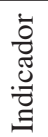 } & Vivienda nueva & 2001 & INE \\
\hline & Vivienda secundaria & 2001 & INE \\
\hline & Vivienda inadecuada & 2001 & INE \\
\hline
\end{tabular}

\section{EL ÍNDICE DE DESFAVORECIMIENTO RURAL COMO PROPUESTA DE MEDICIÓN}

El objetivo último de la elaboración de un IDR en Castilla-La Mancha gira en torno a la detección, reconocimiento y caracterización de territorios homogéneos desde el punto de vista socioeconómico. Como ya se ha mencionado, el modelo que se propone se basa en el establecimiento de un sumatorio final que, dependiendo del valor de las variables, dará como resultado un valor entre 1 y 140, clasificándose cada municipio según los cinco intervalos que proponemos:

- Valores por debajo de 80.0: espacios rurales más dinámicos.

1 Sirvan de ejemplo, la ausencia de datos en el censo de 2011 relativos al nivel formativo y la población vinculada y no residente en municipios de más de 10.000 habitantes; la tasa de vivienda nueva, que sólo ofrece información para municipios superiores a los 50.000 habitantes; la tasa de vivienda secundaria para municipios con más de 2.000 habitantes y la tasa de vivienda inadecuada, que no figura como tal en el censo.

2 Siglas: INE (Instituto Nacional de Estadística), IESCLM (Instituto de Estadística de Castilla-La Mancha), MESS (Ministerio de Empleo y Seguridad Social). 
- Valores entre 80.1 y 90.0: municipios dinámicos, pero con rasgos de desfavorecimiento rural.

- Valores entre 90.1 y 100.0: situaciones intermedias de desfavorecimiento rural.

- Valores entre 100.1 y 110.0: municipios con situaciones acusadas de desfavorecimiento.

- Valores por encima de 110.1: máximo nivel de desfavorecimiento.

El ámbito territorial de estudio abarca el conjunto de municipios de la comunidad autónoma de Castilla-La Mancha, con dos excepciones. Por un lado, los municipios que superan los 10.000 habitantes en el año 2015 -40 localidades-, ya que desde el punto de vista demográfico se consideran territorios que responden a las características de hábitat urbano, quedando categorizados en cuatro niveles (Cebrián, 2008): en el primer nivel se situaría la ciudad de Albacete (172.426 habitantes en 2016); en el segundo poblaciones entre los 50.000 y 100.000 habitantes -6 ciudades-; en el tercero, las ciudades entre los 20.000 y los 50.000 habitantes -9 ciudades-; y en el último, los municipios entre 10.000 y 20.000 habitantes -24 ciudades-. Por otro, dos comunidades de municipios en donde la dificultad de acceso a los datos socioeconómicos ha provocado la ausencia de resultados utilizables en nuestra metodología: Aldovera en la provincia de Guadalajara y Dehesa de Santiago en la de Albacete (Figura 1).

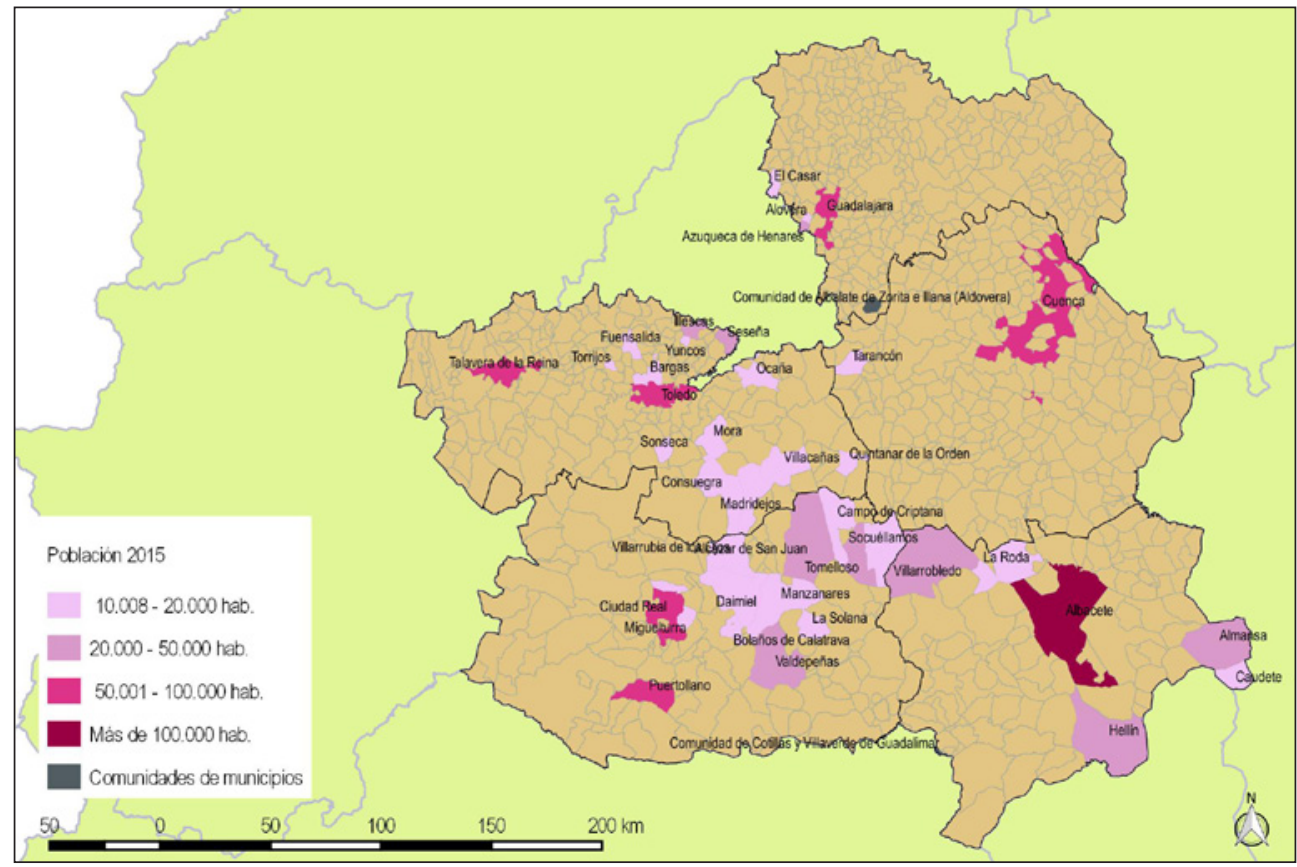

Fuente: INE. Padrón de habitantes 2015. Elaboración propia. 


\section{III.1. La incidencia de los criterios demográficos}

Con el fin de examinar los posibles desequilibrios demográficos en el territorio regional se recurre al análisis de la evolución de la población en cada uno de los municipios desde principios del s. XXI hasta el momento actual. A esta variable esencial se han añadido otros indicadores como: el nivel de envejecimiento de la población, ya que la tendencia demográfica general apunta a un aumento considerable de población con más de 65 años y una reducción drástica del número de nacimientos; la tasa de reemplazo de los efectivos, especialmente a través de la presencia del género femenino en el medio rural, hecho que muestra una fuerte masculinización en la mayoría de los municipios; el indicador del nivel formativo, centrado especialmente en los estudios de educación secundaria; y la población extranjera en estos territorios, que supone, en algunos casos, un ligero incremento del volumen total de efectivos.

\section{III.1.1. La evolución de la población en el período 2001-2015}

Tomando como referencia los primeros quince años del siglo, y teniendo en cuenta la información del censo de 2001 y la revisión del padrón de 2015, se ha analizado la evolución de la población en cada uno de los municipios mediante el cálculo de una tasa de incremento anual.

Los municipios con una evolución más positiva de la población, con un mayor dinamismo demográfico, corresponden con poblaciones localizadas en el oeste de la provincia de Guadalajara -el Corredor del Henares-, así como con el norte de la provincia de Toledo, es decir, poblaciones limítrofes o cercanas a la Comunidad de Madrid. Con estos valores encontramos también municipios cercanos a las principales capitales de provincia o concentraciones urbanas y algunos núcleos en la Sierra Norte de Guadalajara (Figura 2).

El mayor número de municipios $[658,(74,9 \%)]$ ha experimentado un doble comportamiento: o bien un estancamiento demográfico en buena parte de los núcleos de población entre el año 2001 y 2015; o bien, un ligero, casi imperceptible, crecimiento del volumen de efectivos.

El 6,1\% de los municipios (54) se concentran fundamentalmente en las provincias de Cuenca y de Guadalajara, en el Sistema Ibérico, y tienen una pauta demográfica decreciente (del Romero y Valero, 2015). En el caso de Cuenca, se trata de municipios de la Serranía, el valle del río Cabriel, territorios de transición a La Mancha, el Campichuelo y la comarca de La Alcarria. En Guadalajara destacan las concentraciones en las parameras de Molina y el Alto Tajo, un conjunto de pueblos al oeste de Sigüenza y al norte de Brihuega, y localidades de la Sierra Norte. Los valores más negativos aparecen en un total de 24 municipios $(2,7 \%)$ que se localizan mayoritariamente en zonas montañosas de las provincias de Cuenca, Guadalajara y Albacete, situadas en varias comarcas: la Serranía de Cuenca, el Alto Tajo, y las parameras de Molina.

Estos datos ponen de manifiesto que los núcleos menos dinámicos desde el punto de vista demográfico y con una fuerte despoblación se sitúan en los bordes montañosos de la región, aunque a esta pauta generalizada habría que añadir las áreas de transición a La Mancha, especialmente en la provincia de Cuenca, y La Alcarria. 


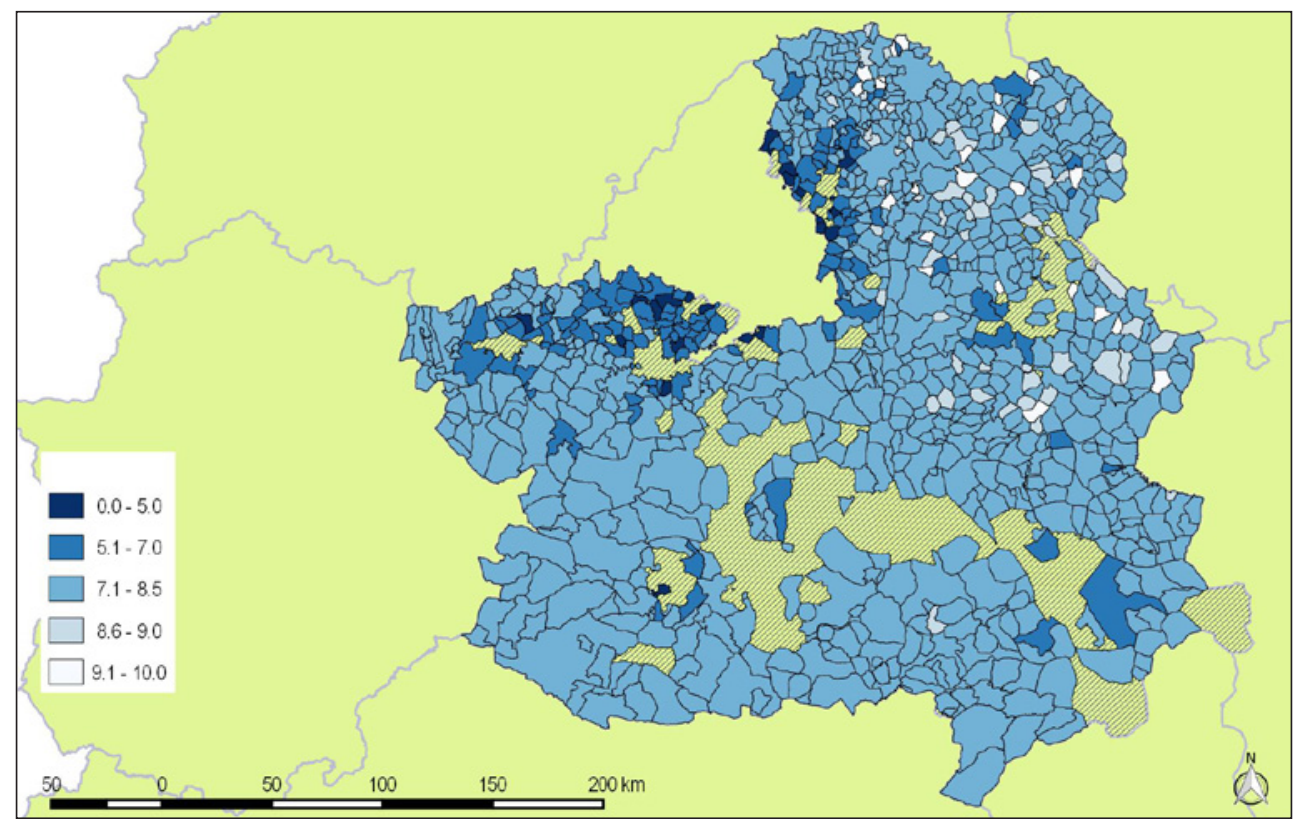

Fuente: INE. Padrón de habitantes 2015. Elaboración propia.

\section{III.1.2. El envejecimiento de la población. Año 2015}

Con este indicador, que calcula el porcentaje de habitantes de 65 años y más sobre el total de la población municipal en 2015, se pretende constatar un hecho característico de la dinámica demográfica de los territorios rurales: el acusado envejecimiento.

La representación cartográfica de la tasa de envejecimiento pone de manifiesto un marcado desequilibrio demográfico. Los valores superiores se corresponden con un total de 83 municipios $(6 \%)$, fundamentalmente de las provincias de Guadalajara y Cuenca, especialmente en las comarcas de La Alcarria y la Serranía, y algún caso aislado en la zona de La Jara toledana (Figura 3). En definitiva, los principales problemas de envejecimiento, que en algunos casos y según autores se trataría de sobreenvejecimiento (Camarero, 2009), se acentúan en la zona oriental de la comunidad autónoma presentando algunas comarcas verdaderos problemas de estrangulamiento demográfico.

Por contraste, los tonos más claros, asociados a los niveles más bajos de envejecimiento, se sitúan en la aureola próxima a la Comunidad de Madrid o próximos a concentraciones de población superiores a los 50.000 habitantes. Ciudad Real, Albacete y Toledo, salvo núcleos puntuales localizados en los bordes montañosos, reflejan valores medios y bajos de envejecimiento, lo que indica que la población joven se concentra en la comarca natural de La Mancha y, por extensión, en sus inmediaciones, así como en las áreas de influencia de las principales capitales de provincia y núcleos más poblados del territorio regional. 


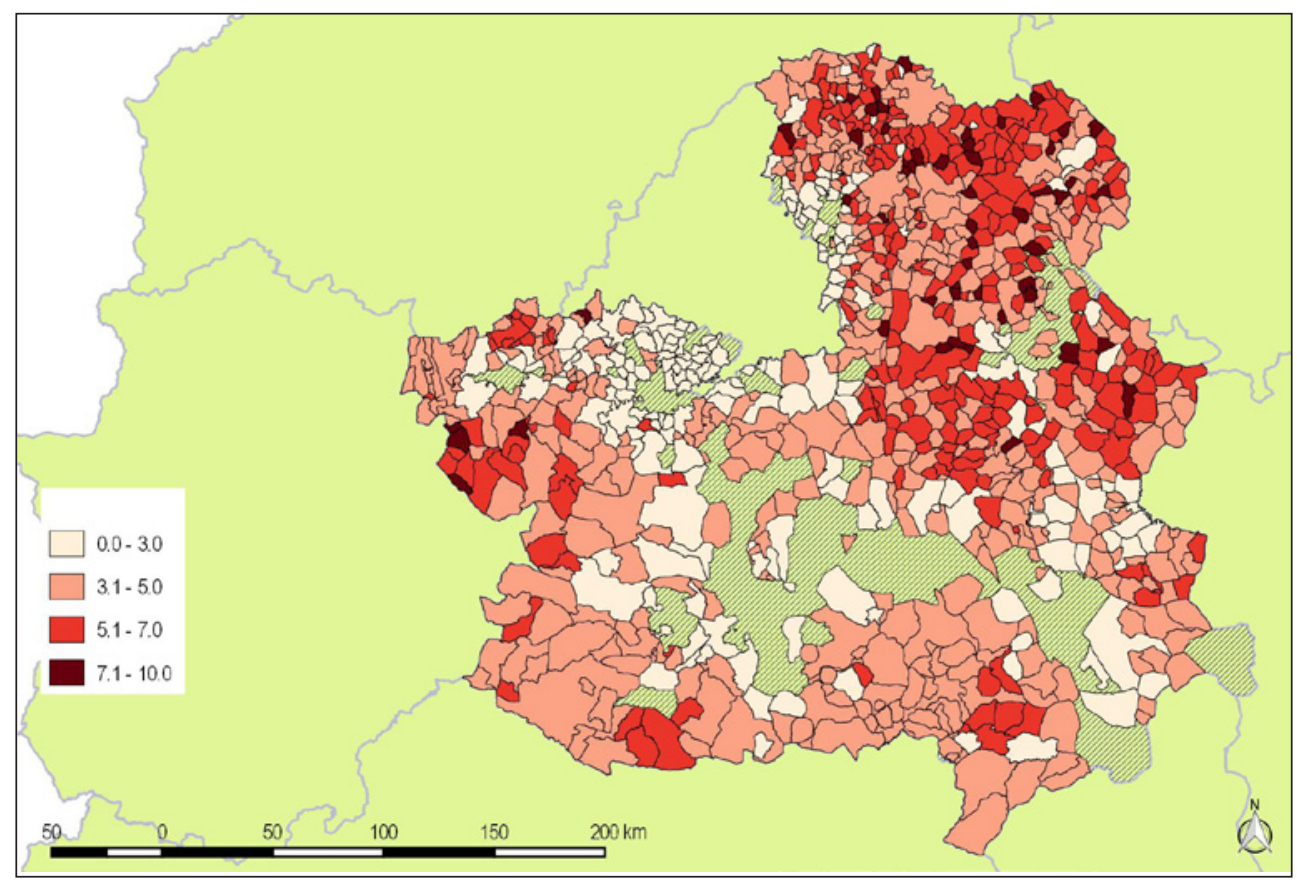

Fuente: INE. Padrón de habitantes 2015. Elaboración propia.

\section{III.1.3. El reemplazo poblacional. Año 2015}

La masculinización progresiva del mundo rural es, junto con el envejecimiento, otra de las características demográficas propias de las zonas desfavorecidas y de su estructura social. Este hecho habría que sumarlo a la variable demográfica de la fecundidad, la cual presenta unos valores imperceptibles por el impacto del envejecimiento social (González y San Miguel del Hoyo, 2001).

La existencia de un número considerable de mujeres mayores de 65 años, y por tanto el más bajo reemplazo poblacional, se detecta en un 35,3\% (312) de los municipios y se concentran, como en casos anteriores, en las provincias de Cuenca -La Alcarria, Serranía y municipios de transición a La Mancha- y Guadalajara -Sierra Norte, parameras de Molina y comarca del Alto Tajo-, aunque también de manera puntual en las provincias restantes. En Albacete abarca zonas montañosas de la Sierra de Segura y Alcaraz y municipios de La Manchuela albaceteña. En Toledo, la parte central de la provincia, los núcleos próximos a la capital, la comarca de La Jara y la Sierra de San Vicente. En Ciudad Real, las proximidades del Valle de Alcudia, Los Montes de Toledo y el campo de Montiel.

Los núcleos más dinámicos desde el punto de vista del reemplazo generacional suponen algo menos del $5 \%$ del total. 


\section{III.1.4. El nivel formativo. Año 2001}

El nivel educativo y cultural de la población presenta interacciones claras con las destrezas de los habitantes y su capacidad para poner en marcha iniciativas sociales y económicas, así como con un aumento de la mano de obra especializada (Aparicio, 2001). Con el cálculo de este indicador se pretende establecer una tasa que recoge el porcentaje de población con el nivel de estudios de secundaria sobre el total de población. La imposibilidad de disponer de datos recientes a escala municipal nos ha obligado a recurrir a información del censo de 2001.

\section{TASA NIVEL FORMATIVO (EDUCACIÓN SECUNDARIA)}

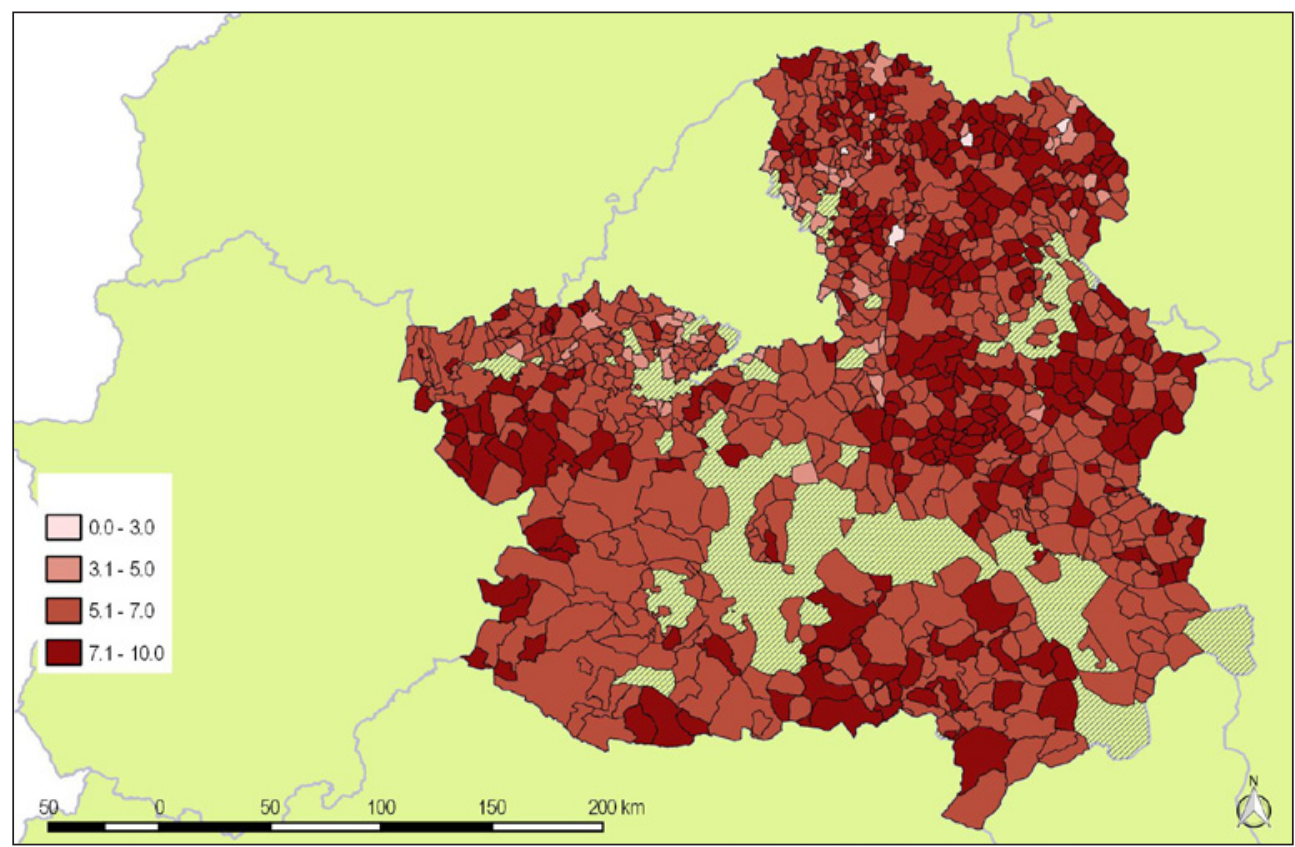

Fuente: INE. Padrón de habitantes 2015. Elaboración propia.

De manera global, los valores próximos a 10 de la escala normalizada, los núcleos con menor población con estudios de educación secundaria responden a un patrón territorial que se sitúa preferentemente en las provincias de Toledo -Los Montes de Toledo y comarca de La Jara-, Cuenca -Serranía, La Alcarria y transición a La Mancha-, y Guadalajara -La Alcarria, Alto Tajo y parameras de Molina- (Figura 4). Esta pauta general de localización no excluye la presencia puntual de algunos municipios con estos valores en las provincias de Ciudad Real -Valle de Alcudia y Sierra Morena- y Albacete -Sierra de Alcaraz-. Esto indica que las áreas de montaña presentan los porcentajes más bajos de población con estudios de educación secundaria frente a las áreas de influencia de la capital toledana, y la zona norte y oeste de la ciudad de Guadalajara en donde se sitúan los núcleos con mayor peso de población con 
estos estudios, lo que no implica que en el resto del territorio regional se encuentren valores similares, aunque sean testimoniales, y no respondan a una pauta de localización concreta.

\section{III.1.5. La población extranjera. Año 2015}

Aunque la población extranjera no puede considerarse como la panacea para solventar algunos de los problemas demográficos que lastran estas comarcas (envejecimiento, masculinización, reemplazo, fecundidad), hay que tenerla en cuenta como una variable demográfica más (Castro-Martín, 2010).

En este orden de cosas, la tasa que se propone calcula el porcentaje de población extranjera sobre el volumen total de la población del municipio, tomando como referencia el Padrón de 2015. Se podría decir, sin riesgo a equivocarse, que prácticamente toda la región se ha visto afectada en mayor o menor medida por la llegada de población inmigrante, aunque con especial incidencia en las comarcas de La Mancha, La Sagra, la Mesa de Ocaña, el eje de comunicación de la A-2, La Alcarria y el territorio levantino, frente a las zonas montañosas del territorio autonómico. Los efectos que ella ha tenido en las economías locales han dependido, según los casos, de la integración de este grupo de población en sus economías (Comisión Europea, 2006).

\section{III.2. La incidencia de los criterios derivados de la relación de la población con la actividad económica}

El medio rural está experimentando una continua reconversión de sus economías, fundamentalmente agrícolas y ganaderas, como consecuencia de la puesta en marcha de políticas y medidas que apuestan por el sector turístico como pieza clave de la diversificación de sus modelos económicos (Binimelis y Ordinas, 2006; Gambau, 2000).

\section{III.2.1. La población activa. Año 2015}

En este caso el indicador analizado constituye el porcentaje de población activa (afiliados a la Seguridad Social, trabajando y cotizando, más los parados) en relación con la población potencialmente activa total (intervalo 15-64 años). Al amparo de los resultados, el $94 \%$ de los municipios se concentran en los dos últimos intervalos de la escala (7.1 a 9.0 y 9.1 a 10.0), tratándose de los espacios con menor población activa y mayor altitud de la región al ubicarse en áreas montañosas como el Alto Tajo y la Serranía de Cuenca.

\section{III.2.2. La afiliación a la Seguridad Social. Año 2015}

El indicador analizado es el resultado de dividir el porcentaje de afiliados al sistema de la Seguridad Social ${ }^{3}$, tomando como referencia los valores de diciembre de 2015, entre la población potencialmente activa.

3 Se incluyen en este epígrafe, según el Ministerio, el régimen general de afiliados (agrario, mar, hogar), los autónomos y los trabajadores del sector del carbón. 
El intervalo inferior ( 0.1 a 5.0) corresponde con aquellos municipios que mejor tasa de afiliados a la Seguridad Social presentan -6 municipios (0,7\%)- situados en la provincia de Cuenca, en la de Guadalajara, y el municipio toledano de Totanés. Este valor porcentual, prácticamente testimonial, contrasta con los datos del último intervalo (9.110.0) que responde a las localidades peor posicionadas en la tasa normalizada y en la tasa de afiliados a la Seguridad Social, en total 363 municipios $(41,3 \%)$ con una presencia generalizada en las cinco provincias: en Albacete destaca la comarca de la sierra de Alcaraz y La Manchuela; en Ciudad Real, junto al Valle de Alcudia, la comarca de Almadén, Los Montes de Toledo y algunos municipios próximos a concentraciones importantes de población; en Toledo, la sierra de San Vicente, las comarcas de Oropesa, La Sagra y la mesa de Ocaña; en Cuenca, La Alcarria y la Serranía; y en Guadalajara, las comarcas del Alto Tajo, Molina de Aragón, La Alcarria, la Sierra Norte y algunos municipios limítrofes con poblaciones populosas.

\section{III.2.3. La población en situación de paro. Año 2015}

La consideración de esta variable se justifica porque aporta, junto con la tasa de actividad, el volumen de capital humano potencialmente disponible por el mercado laboral en cada uno de los municipios.

En este caso, las tasas de paro más bajas se corresponden con localidades concentradas especialmente en Guadalajara y Cuenca. En la primera en el eje de comunicaciones A-2 y los municipios próximos a la Comunidad de Madrid, alguno situado en la Sierra Norte, y otros pertenecientes a la Tierra de Atienza y al Señorío de Molina; y en la segunda en la comarca del Campichuelo, La Alcarria conquense, el eje de la A-3 (Iniesta) y pueblos de la zona de transición a La Mancha.

Los siguientes intervalos suponen un empeoramiento de los datos de paro, extendiéndose por todo el territorio regional, situándose los valores más negativos en las comarcas toledanas de La Jara y la Sierra de San Vicente, el campo de Montiel en Ciudad Real, las comarcas albaceteñas de las Sierras de Alcaraz y el área levantina, varios municipios conquenses y algunos guadalajareños.

\section{III.2.4. Las empresas dadas de alta en la Seguridad Social. Año 2015}

El indicador calculado para analizar las empresas dadas de alta en la Seguridad Social responde a una tasa de crecimiento que representa el porcentaje de empresas ${ }^{4}$ dadas de alta en la Seguridad Social, tomando como referencia inicial el año 2007 (valor 100) y como año final 2015. Con este cálculo se pretende conocer el comportamiento de las altas empresariales en la Seguridad Social durante estos ocho años, si han aumentado -cuando los índices son superiores a $100 \%-$, o por el contrario han descendido -tasas inferiores al 100\%-.

4 Por empresa se entiende centros de trabajo (centros de cotización), es decir, se contabilizan tanto las sedes principales (sedes sociales) como las sucursales. 
De esta forma, en el análisis municipal, los núcleos con un crecimiento empresarial bajo se localizan en todo el territorio regional, pero con un claro predominio en dos franjas oblícuas: una de ellas dispuesta desde la Sierra Norte de Guadalajara hasta el continuum territorial del Sistema Ibérico, abarcando las parameras de Molina; y otra desde la sierra de San Vicente, en la provincia de Toledo, pasando por la Tierra de La Jara hasta la comarca de Almadén.

Según los indicadores analizados, las comarcas donde menos empresas se han dado de alta en la Seguridad Social corresponden a La Sagra, la Mesa de Ocaña y Los Montes de Toledo; Alto Tajo, Molina y pueblos próximos al eje de comunicación A-2 en Guadalajara; y municipios salpicados por toda la provincia de Cuenca.

\section{III.2.5. La población vinculada y no residente. Año 2001}

Este indicador se calcula dividiendo el porcentaje de población vinculada no residente y que trabaja en un núcleo de población, entre la población que reside y trabaja en el mismo. La no disponibilidad en el censo de 2011 de información relativa a municipios inferiores a los 10.000 habitantes nos ha hecho recurrir a la consulta del censo de 2001 .

Los municipios con mayor población vinculada no residente se encuentran repartidos por las cinco provincias y mayoritariamente próximos a núcleos de población que superan los 10.000 habitantes.

Por el contrario, los municipios con menor población vinculada no residente se sitúan mayoritariamente en la orla montañosa de la región: Sierra Norte, Molina de Aragón y alto Tajo en la provincia de Guadalajara; La Alcarria y especialmente la Serranía en la provincia de Cuenca; Alcaraz en Albacete; borde occidental de la provincia de Ciudad Real; y Sierra de San Vicente y La Jara en Toledo.

\section{III.2.6. Los sectores económicos. Año 2015}

En este epígrafe nos hemos centrado en los sectores primario y terciario y en el capital humano dedicado a actividades agrícolas, ganaderas y de servicios. La tasa que hemos calculado presenta el porcentaje de personas dedicadas al sector servicios en relación con el total de personas vinculadas al sector primario.

El peso de la población vinculada al sector servicios es considerablemente notorio en diecisiete municipios $(1,9 \%)$ de las provincias de Guadalajara y Toledo ubicados en las proximidades de la Comunidad de Madrid (Figura 5).

El peso del sector agrario sobre el sector servicios es claramente dominante en un 94,3\% de los municipios castellano-manchegos (820) repartidos por toda la geografía regional: sector central, cabeceras comarcales y Sierra Norte de Guadalajara; La Alcarria, algunos municipios situados en los principales ejes de comunicación y Serranía de Cuenca; sierra de Alcaraz y del Segura en la provincia de Albacete; municipios de la Tierra de Calatrava en la provincia de Ciudad Real; y comarca de Oropesa y pueblos del sector central de la provincia de Toledo. 


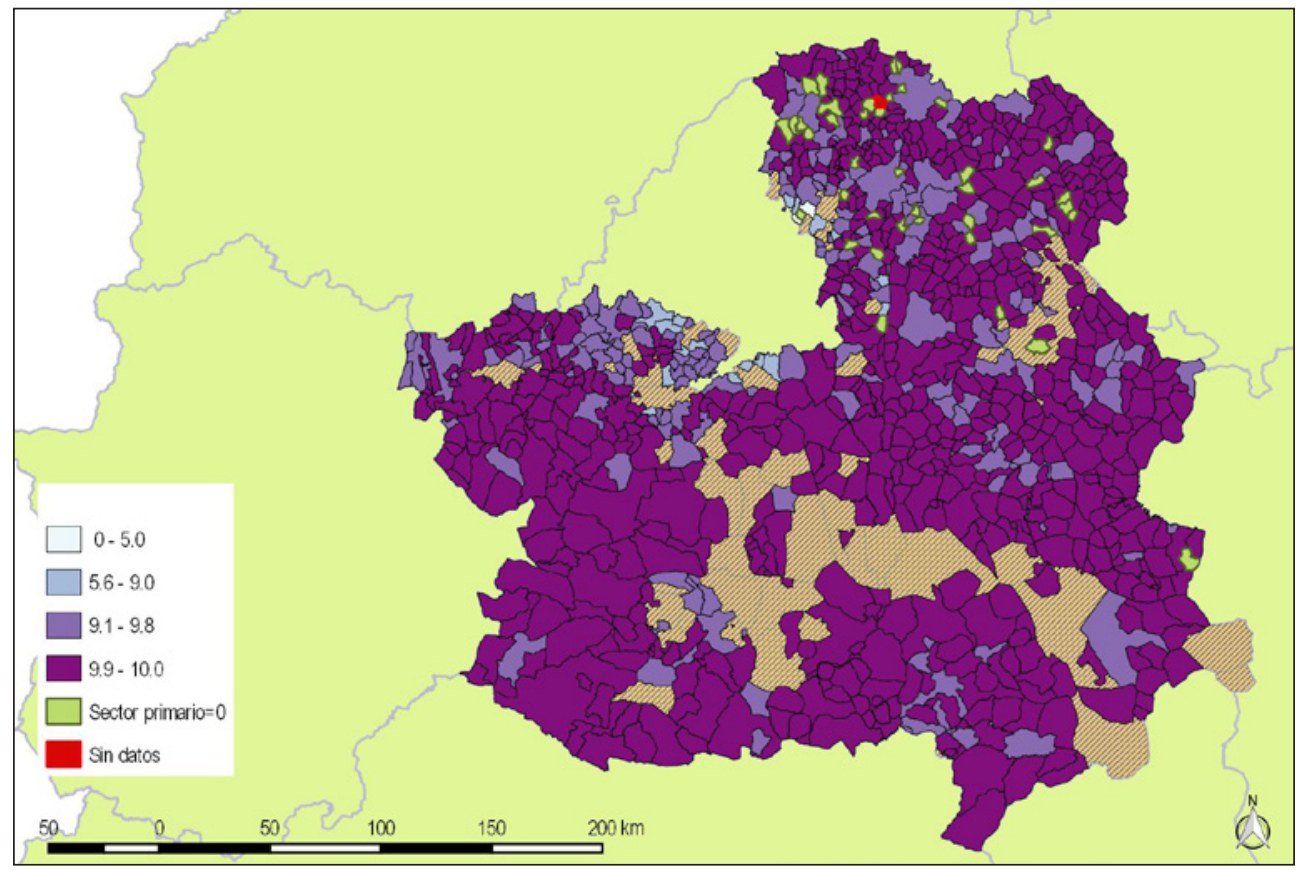

Fuente: IESJCCM 2015. Elaboración propia.

\section{III.3. La incidencia de los criterios vinculados a las características del parque residencial}

Con este último apartado pretendemos conocer el dinamismo en la renovación del parque residencial a nivel municipal, teniendo en cuenta la vivienda principal y también la secundaria. Para ello hemos analizado tres indicadores referidos al censo de 2001 puesto que las limitaciones del censo de 2011 nos han impedido obtener información más actual. El primer indicador está relacionado con la vivienda nueva, el segundo con la vivienda secundaria y el tercero con el estado de la vivienda.

\section{III.3.1. La vivienda nueva. Año 2001}

Los municipios con valores más elevados de vivienda nueva en el periodo 1991-2001 se distribuyen geográficamente cumpliendo un doble patrón: o bien en la zona oeste de la provincia de Guadalajara y el norte de la provincia de Toledo, siempre en el límite de contacto con la Comunidad de Madrid; o bien en la orla periurbana de las capitales de provincia que se han visto afectadas por procesos de urbanización en la última década.

Los municipios con menor proporción de vivienda nueva se concentran fundamentalmente en las provincias de Guadalajara y Cuenca. 


\section{III.3.2. La vivienda secundaria. Año 2001}

La tasa de vivienda secundaria representa el porcentaje de segunda residencia respecto al total de vivienda familiar. Así, entendemos que cuanto mayor es el porcentaje de segunda residencia más dinámica será la construcción y la rehabilitación en el núcleo. La segunda residencia supone la presencia de población estacional en el municipio, generalmente ligada al turismo y al ocio, que también demanda bienes y servicios de primera necesidad, lo que implica un cierto grado de dinamismo económico de los núcleos rurales durante algunos períodos anuales.

Los municipios con porcentajes escasos de vivienda secundaria se concentran principalmente en el centro de la región, aunque se extienden hacia comarcas como La Sagra y La Manchuela. Un buen número de municipios se localiza también en el sector nordeste de la provincia de Toledo (Ocaña, Polán ...), que han visto crecer su parque de vivienda familiar al amparo del desarrollo urbanístico del sur de la Comunidad de Madrid.

Las provincias de Guadalajara y Cuenca, con escasas excepciones (borde de contacto con Madrid y franja meridional de La Mancha), presentan elevados porcentajes de vivienda secundaria, bien por constituir el parque residencial vinculado a los periodos de ocio y vacacionales de población emigrada de estos núcleos, o bien por haber sido construidas o rehabilitadas por población alóctona que disfruta de periodos de descanso en estas localidades. A esta pauta de distribución se sumarían municipios de las sierras de Alcaraz y Segura, Los Montes de Toledo y valle de Alcudia (Figura 6).

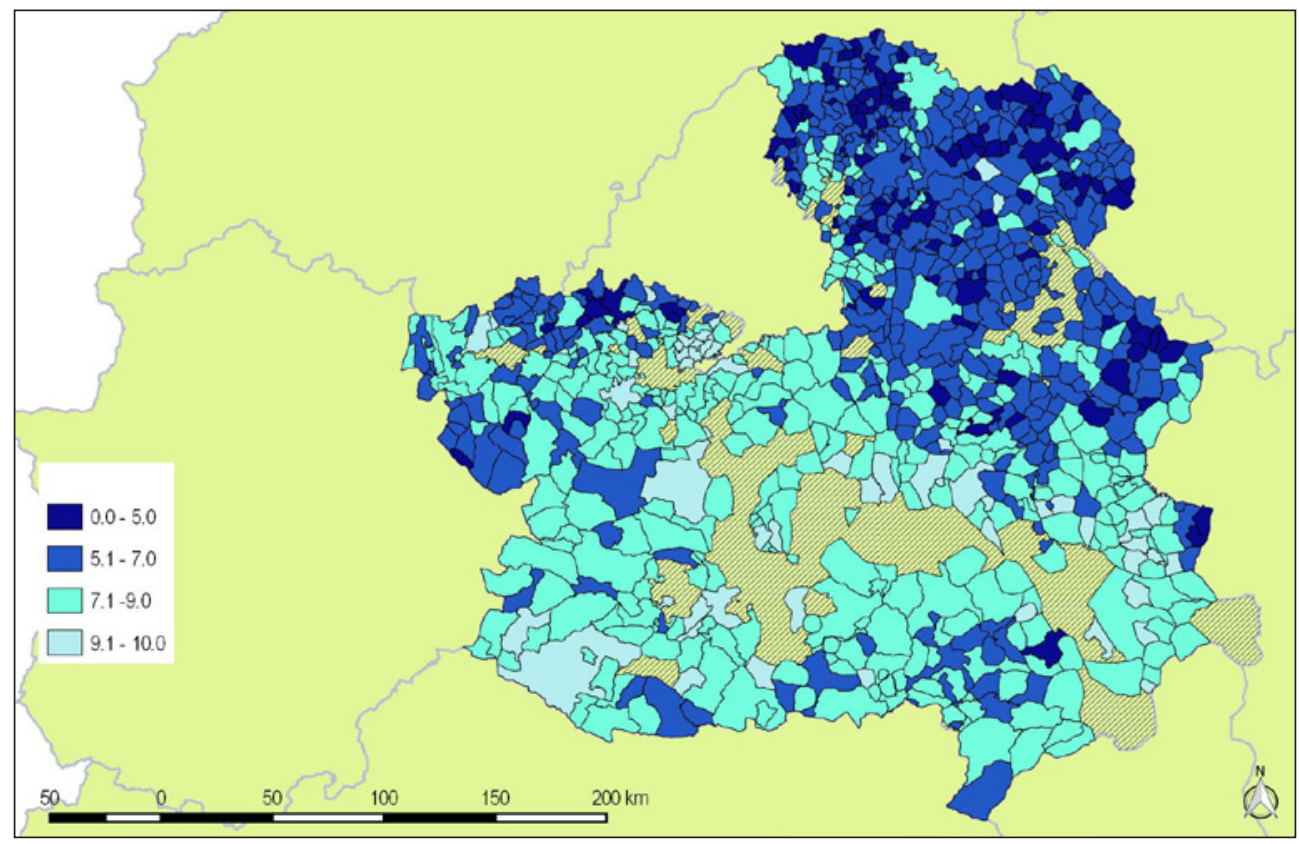

Fuente: INE. 2001. Elaboración propia. 


\section{III.3.3. El estado de la vivienda. Año 2001}

Según el censo de 2001, se considera vivienda inadecuada al sumatorio de todas aquellas que presentan las calificaciones de ruinosa, mala o deficiente en relación con el total de vivienda.

Este indicador muestra que buena parte de la región -un 95,1\%, 836 núcleos- tiene el parque de vivienda en condiciones aceptables u óptimas, mientras que sólo 43 municipios $(4,9 \%)$ presentan peores condiciones, destacando las provincias de Guadalajara y Cuenca con 16 y 11 municipios respectivamente. En Cuenca encontramos los peores valores de la región y en Guadalajara el mayor número de municipios con viviendas en mal estado, aunque sus municipios no alcanzan valores extremos en la tasa normalizada.

\section{EL DESFAVORECIMIENTO RURAL EN CASTILLA-LA MANCHA}

Llegados a este punto, y tras calcular los valores normalizados para las catorce variables en todos los municipios castellano-manchegos, hemos calculado el sumatorio total de los valores de las variables en cada una de las localidades, representando los IDR de 2011 y 2015 en las Figuras 7 y 8.

Para ello hemos establecido cinco intervalos que nos permitirán clasificar la situación de cada uno de los municipios rurales, con un valor mínimo registrado que oscila entre los 59.7 puntos -año 2015-y los 63.7 -año 2011-, y un valor máximo situado en los 120 puntos para ambos años no superado por ninguna localidad.

- En el tramo inferior (0.0-80.0), con un índice de desfavorecimiento muy bajo, aparecen los espacios rurales más dinámicos. En el año 2011, correspondía con 19 municipios $(2,2 \%)$ repartidos por todo el territorio regional. Buena parte de ellos se localizan en la provincia de Guadalajara distribuidos por todas las comarcas: parameras de Molina, alto Tajo, Sierra Norte y Tierra de Atienza, pero sobre todo en el corredor de comunicaciones del Henares, muy próximo a la capital alcarreña. En general, estos municipios presentan la peculiaridad de contar con un término municipal de superficie reducida.

- El siguiente intervalo (80.1-90.0) correspondería con municipios dinámicos pero con ciertos rasgos de desfavorecimiento. En el año 2011 sumaban 81 municipios $(9,2 \%)$ situándose en Cuenca -Iniesta y Alarcón-, Toledo -Maqueda- y Guadalajara -Trillo-. Por el contrario, en el año 2015 son 31 (3,5\%) las localidades con estos valores, encontrando ejemplos fundamentalmente en las provincias de Guadalajara y Cuenca. En el primer caso (19) están repartidos por todo el territorio provincial especialmente en la comarca de Molina de Aragón, en el sector occidental, en las zonas periurbanas de núcleos populosos próximos a la Comunidad de Madrid y en la Sierra Norte. En el segundo caso, destacan cuatro ejemplos, tres de ellos situados en las estribaciones de La Alcarria y el cuarto en el eje de comunicaciones de la A-3, autovía de Valencia o autovía del Este. Cabe subrayar los ocho municipios de la provincia de Toledo localizados en el sector central muy próximos a núcleos que superan los 10.000 habitantes. 
- La tercera franja (90.1-100.0) responde a situaciones intermedias de desfavorecimiento. En 2011, este intervalo suponía el 50\% de todos los municipios analizados, más de 440 pueblos repartidos por las cinco provincias, aunque con especial incidencia en comarcas como la llanura manchega, la comarca de Hellín, las proximidades de Sierra Morena, Los Montes de Toledo, la comarca de Talavera, la comarca de La Sagra, la mesa de Ocaña, la Serranía de Cuenca, el Campichuelo, La Alcarria conquense, La Mancha Alta y los municipios de transición a La Mancha, La Manchuela conquense y la zona levantina, la comarca de las parameras de Molina, el Alto Tajo, la Sierra Norte, La Alcarria de Guadalajara e incluso poblaciones con cierta entidad de población (Sigüenza, Brihuega). Sin embargo, el descenso en el número de poblaciones con estos valores en el año 2015 es considerable, pasando al 31,2\% (274 localidades), aunque muchas entidades se mantienen en el mismo intervalo como Herencia, Mota del Cuervo, Chinchilla y Sigüenza, entre otras.

- Se ha considerado el valor 100 como punto a partir del cual las situaciones socioeconómicas se caracterizan por un acusado nivel de desfavorecimiento. Así pues, el intervalo 100.1 a 110.0 recoge para el año 2011 un total de 326 municipios (37\%) y sus respectivas comarcas: Sierra de San Vicente, comarca de Oropesa, comarca de La Jara toledana, Los Montes de Toledo, Almadén y su comarca, Valle de Alcudia, Sierra Morena, campo de Montiel, sierra de Alcaraz y del Segura, comarca albaceteña del Sureste, Serranía de Cuenca, La Alcarria, Alto Tajo y comarca de Molina. En 2015 el número de municipios con valores en este intervalo ha aumentado a $531(60,4 \%)$, afectando también a todo el territorio, lo que indica un cierto empeoramiento de la situación de desfavorecimiento de la región.

- Los municipios con índices normalizados superiores a 110 se encontrarían en el máximo nivel de desfavorecimiento. En el año 2011, sólo 10 municipios se incluyeron en esta franja. Aunque su valor porcentual es prácticamente testimonial $(1,1 \%)$, su localización espacial confirma la pauta general de marginación territorial que ya apuntaban los dos intervalos precedentes. Tan solo cuatro años después, en 2015 , son 39 los municipios $(4,4 \%)$ con índices de desfavorecimiento superiores a 110 , evidenciándose un incremento considerable de entidades con este nivel máximo de desfavorecimiento relacionado con la crisis económica, que puede observarse en el oscurecimiento de algunos términos municipales en la Figura 8 respecto a la 7 .

Como se desprende de la cartografía analizada para el período 2011-2015, las tonalidades más claras, que identifican los espacios rurales más dinámicos y con menos problemas de desfavorecimiento, se concentran mayoritariamente en las proximidades de los principales núcleos de población de la región -La Mancha, capitales de provincia, zonas limítrofes con Madrid, La Sagra, el Corredor del Henares-, y gozan en conjunto de mejores soluciones sociales y económicas para poder hacer frente a los problemas estructurales que afectan al medio rural. Los tonos intermedios - próximos a 100- se distribuyen por todo el territorio regional sirviendo en algunos casos de continuación o colchón hacia zonas más desfavorecidas, como son los casos del centro de la provincia de Toledo, la mesa de Ocaña-Tarancón, las poblaciones próximas a concentraciones de población en La Mancha, La Manchuela conquense y albaceteña, las zonas colindantes con Madrid de las provincias de Guadalajara y Cuenca, las aureolas de capitales de provincia y los municipios que ejercen las funciones de 
cabeceras comarcales (Sigüenza, Molina de Aragón, Brihuega), aunque este análisis general incluye algunas excepciones que corresponden con municipios que presentan sus propias dinámicas económicas y sociales como ejemplifican algunos casos en la Sierra de Segura y de Alcaraz, y poblaciones de la Serranía de Cuenca y del Alto Tajo.

Si comparamos ambas figuras y nos centramos en el análisis de los valores más elevados del índice (100.1-110.0), la pauta espacial en 2011 responde a un doble modelo: por un lado, una curva que se dibuja desde el borde occidental de la provincia de Toledo (comarca de Oropesa, La Jara y Los Montes de Toledo al norte), pasando por los sectores occidental y meridional de la provincia de Ciudad Real (flanco sur de Los Montes de Toledo, Valle de Alcudia, Sierra Morena), para conectar con la provincia de Albacete a través del Campo de Montiel, llegar a las Sierras de Alcaraz y del Segura y finalizar en La Manchuela albaceteña; y por otro lado, las provincias de Cuenca y Guadalajara, donde la distribución espacial de los municipios en situación de crisis estructural no responde a una pauta clara, sino a una dispersión en el territorio provincial. En cambio, en el año 2015, se asiste claramente a un empeoramiento de muchos municipios, especialmente del flanco occidental de la región (comarca de La Jara, Los Montes de Toledo, comarca de Almadén, Sierra Morena, Sierra de Alcaraz) y de otras zonas como La Alcarria conquense, La Manchuela, Señorío de Molina y Alto Tajo. Hay que subrayar el notable incremento de municipios en la última franja del índice que responden principalmente a localizaciones de montaña. Esto lleva a pensar que durante estos años se ha acentuado, si cabe todavía más, la situación crítica de estas localidades.

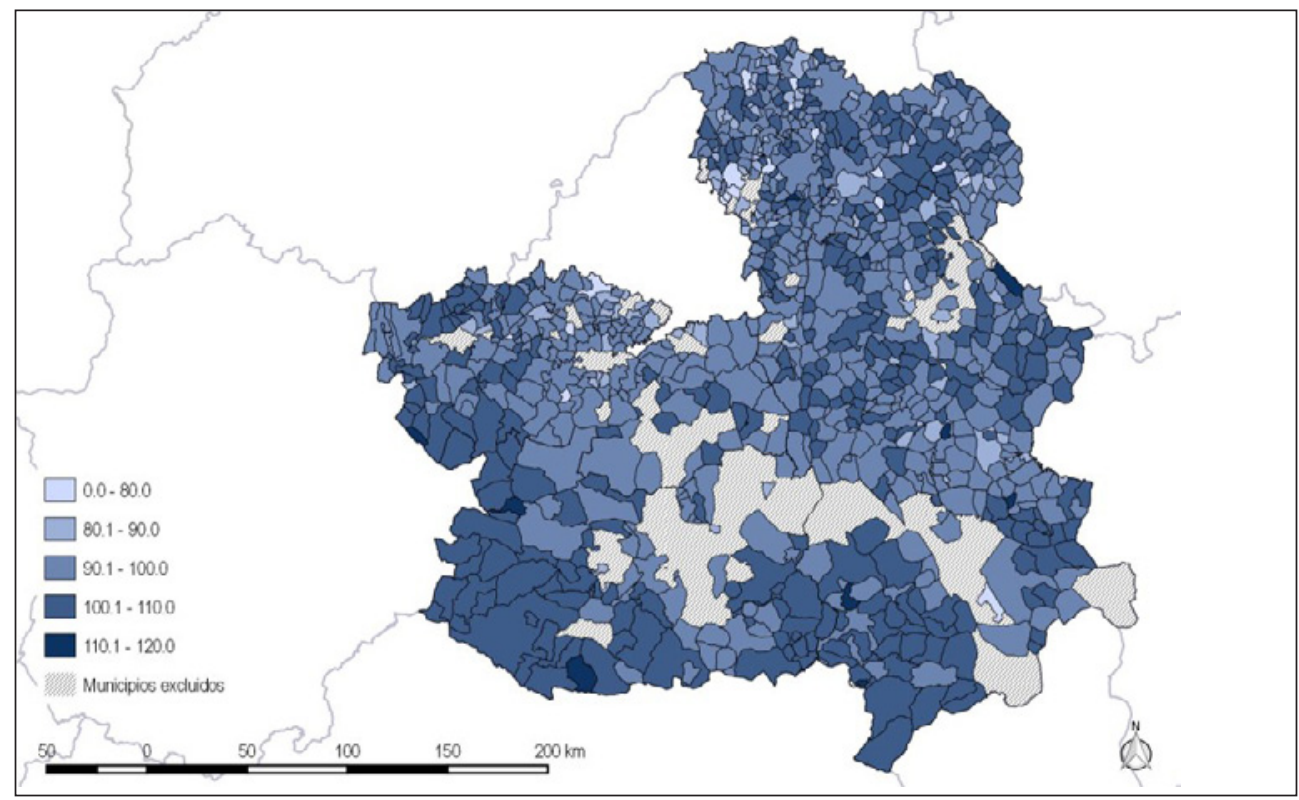

Fuente. Elaboración propia. 


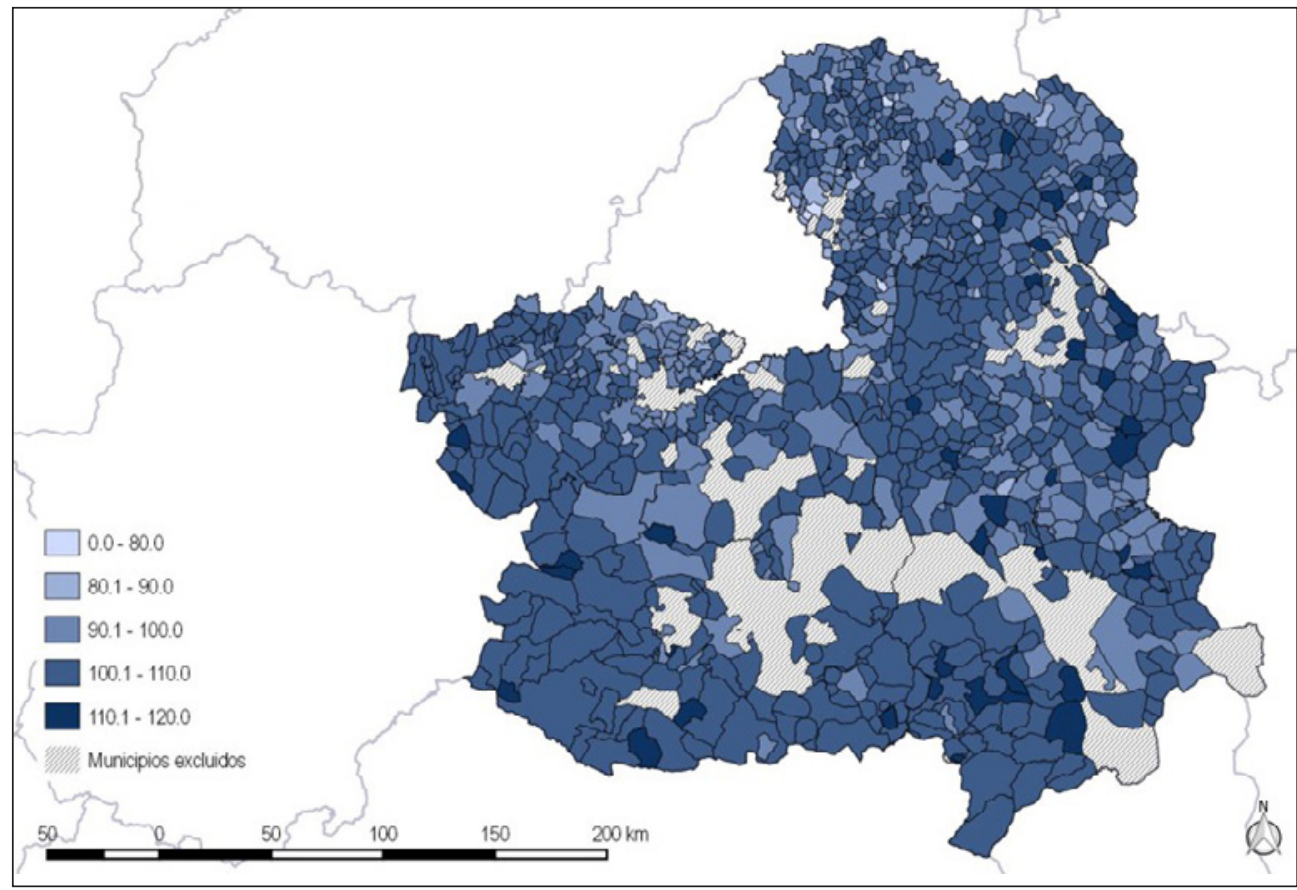

Fuente. Elaboración propia.

En síntesis, se podría decir que las comarcas montañosas del territorio (Los Montes de Toledo, Serranía de Cuenca, Sierra Norte de Guadalajara, Sierra de Alcaraz, Valle de Alcudia, Sierra Morena) se perfilan como las más desfavorecidas en 2011, situación que se ve agudizada en 2015. No obstante, también encontramos desfavorecimiento en La Mancha, los municipios próximos a las capitales de provincia o limítrofes con las comarcas próximas a la Comunidad de Madrid (La Sagra, el Corredor del Henares) y La Manchuela. En cualquier caso, y como ya se ha apuntado anteriormente, algunos núcleos de población con índices muy bajos no responden a las pautas espaciales descritas más arriba, sino que deben su posición a sus propias dinámicas demográficas, socioeconómicas y funcionales.

\section{CONCLUSIONES}

El establecimiento de un IDR para cada uno de los municipios rurales de Castilla-La Mancha mediante el cálculo de unas tasas relacionadas con criterios demográficos, económicos y residenciales, y la consideración del indicador 100 como valor a partir del cual se evidencia la existencia de situaciones de considerable desfavorecimiento, nos lleva a identificar la existencia de una clara dicotomía socioeconómica en el territorio analizado: un 64,8\% del espacio regional (570 municipios) con valores superiores a 100 muestra problemas evidentes 
en lo demográfico, lo económico y lo residencial, y un 35,2\% (309 municipios) presenta situaciones menos alarmantes y más dinámicas que gozan de un bajo nivel de crisis rural. Los espacios con un elevado IDR se caracterizan por unas bajas densidades de población, constituyendo en algunos casos auténticos desiertos poblacionales (Serranía de Cuenca, comarca del Alto Tajo y Señorío de Molina), lo que incide en un abandono progresivo de gran parte de las actividades productivas tradicionales, fundamentalmente agrícolas y ganaderas; el envejecimiento acusado de sus habitantes que, unido a la variable anterior, provoca un auténtico cambio demográfico en las poblaciones rurales, aumentando el número de personas que viven solas y que demandan mayores atenciones (sociales, económicas, etc.); la disminución de la fecundidad, que ha provocado en muchos casos la imposibilidad de un relevo generacional y un desequilibro demográfico que no tiene, según algunos autores, indicios de corregirse (Maya Frades, 2004: 287); el predominio del nivel educativo en estudios primarios, lo que se traduce en bajos niveles de cualificación laboral (Goerlich, Mas y Dirs, 2007); y la escasa presencia de contingentes de población extranjera en los territorios, que atenúan, cuando existen, el impacto de los desequilibrios demográficos dominantes. La ausencia de una buena cobertura en infraestructuras para conexión a internet y la falta de infraestructuras de transportes y de comunicación agudizan la brecha tecnológica y territorial.

Son áreas que en la mayoría de los programas y medidas sectoriales constituyen objetivos prioritarios con el fin de revitalizar sus economías. En general, corresponden a comarcas y municipios de áreas de montaña con unas economías dominantes y propias del sector primario que han buscado, en algunos casos, el despegue turístico apoyado en marchamos de calidad natural como los espacios naturales protegidos: la comarca de Los Montes de Toledo -parque nacional de Cabañeros-, la Serranía de Cuenca -parque natural-, la Sierra Norte de Guadalajara -parque natural-, la sierra de Alcaraz y el Segura -parque natural de los Calares del río Mundo-, y Alto Tajo -parque natural-, entre otros. El desarrollo de estas zonas rurales desfavorecidas pasa por la puesta en marcha de estrategias globales que impliquen a todos los agentes sociales del territorio así como a las diversas administraciones de la comarca, abarcando aspectos sociales, económicos, financieros, medioambientales, culturales y patrimoniales, teniendo en cuenta que prácticamente la única oportunidad para conseguir su despegue económico pasaría por la valorización de sus entornos naturales y la conservación de los mismos. En este sentido, el medio rural ofrece una diversidad de paisajes y de modos de vida que como recursos son incuestionables (Martínez Arnáiz, 2004: 607), y donde el paisaje debe tener y jugar un papel fundamental por ser punto de encuentro entre realidades naturales/ medioambientales-sociales/económicas (Galindo Pérez de Azpillaga, 2004).

El índice de desfavorecimiento rural ha mostrado una situación más favorable en el resto de comarcas, aunque como se ha podido comprobar en la evolución temporal, en general el empeoramiento en los años analizados ha sido notable. Los territorios centrales y de transición a la montaña cuentan con una mejor situación socioeconómica frente a los espacios de acusada ruralidad. La mayoría de estas comarcas presentan mejores valores en los criterios económicos, como es la afiliación de trabajadores y de empresas a la seguridad social, lo que se traduce en un mayor dinamismo con un claro dominio del sector servicios, reduciéndose, en muchos casos, el peso de la agricultura y de la ganadería. Son áreas vinculadas al desarro1lo industrial próximas a los núcleos de población de más de 10.000 habitantes. Es el caso de La Sagra en la provincia de Toledo, en donde el modelo de industrialización rural dispersa y 
difusa ha aprovechado el potencial de los sectores económicos exógenos de la vecina Comunidad de Madrid. Algo similar podría argumentarse de los municipios localizados en los ejes de comunicación de primer orden, lo que beneficia el arraigo de la población a su territorio. Al amparo de estos desarrollos económicos, sociales e industriales, sus parques residenciales se han visto incrementados, mientras que ese efecto es prácticamente imperceptible en las zonas desfavorecidas, salvo en algún caso puntual. Por el contrario, el peso de la vivienda secundaria se sitúa principalmente en las áreas de mayor ruralidad, espacios de descanso y de ocio asociados fundamentalmente a zonas montañosas.

\section{BIBLIOGRAFÍA}

APARICIO, A. E. (2001): «Desarrollo local y turismo rural: La Alcarria Conquense». Ería, $\mathrm{n}^{\mathrm{o}} 54-55,18-24$.

BINIMELIS, J. y ORDINAS, A. (2006): «El turismo rural y las actividades de recreación como solución a los problemas de la agricultura en las Islas Baleares», en AA. VV., Actas del X Coloquio de Geografía del Turismo, Ocio y Recreación. Cuenca. Universidad de Castilla-La Mancha, pp. 473-480.

BRUQUETAS, M., MORENO, F. J. y WALLISER, A. (2005). La regeneración de barrios desfavorecidos. Colección Laboratorio de Alternativas, $N^{\circ}$ 67. Fundación Alternativas. Disponible en http://www.falternativas.org/base/download/14ed_14-09-05_672005.pdf

CAMARERO, L. (2009): La población rural de España. De los desequilibrios a la sostenibilidad social. Barcelona. Obra social fundación La Caixa.

CASTRO-MARTÍN, T. (2010): «¿Puede la inmigración frenar el envejecimiento de la población española? ». Análisis del Real Instituto Elcano, n 40, 1-11. Disponible en https:// dialnet.unirioja.es/servlet/articulo?codigo $=3187941$

CEBRIÁN, F. (2008): «Articulación del territorio: Las ciudades en Castilla-La Mancha». Idea La Mancha. Revista de Educación de Castilla-La Mancha, $\mathrm{n}^{\circ}$ 6, 278-285.

CLOUT, H. (1993). «What Is the Rural?», en CLOUT, H (dd.), European Experience of Rural Development. Londres: The Rural Development Commission, mimeo.

COATES, B. E., JOHNSTON, R. J. y KNOX, P. L. (1977): Geography and Inequality. Oxford. Oxford University Press.

COMISIÓN EUROPEA (2006). El futuro demográfico de Europa: transformar un reto en una oportunidad. COM (2006) 571, Bruselas.

COX, K. R. (1979): Location and Public problems: a Political Geography of the Contemporary World. Oxford: Basil Blackwell.

CUADRADO-ROURA, J. R., YSERTE, R. G. y MANCHA, T. (1999): «Disparidades Regionales y Convergencia en España. 1980-1995». Revista de Estudios Regionales, $\mathrm{n}^{\circ}$ $55,109-137$.

CULLINGFORD, D. y OPENSHAW, S. (1982): «Identifying areas of rural deprivation using social area analysis». Regional Studies, $\mathrm{n}^{\circ}$ 16, 409-418.

DEL ROMERO, L. y VALERO, A. (2015): «Teruel, territorio en decrecimiento: dinámicas y oportunidades». Revista de Estudios sobre Despoblación y Desarrollo Rural, $\mathrm{n}^{\circ} 19$, 85-116. Disponible en https://doi.org/10.4422/ager.2015.09 
DUNN, J., HODGE, I., MONK, S. y KIDDLE, C. (1998): Developing indicators of rural disadvantage: final report to the Rural Development Commission. Cambridge. Department of Land Economy.

GALINDO, L. (2004): «El paisaje en la Vega Media de Sevilla como elemento determinante en una nueva percepción de los espacios rurales», en AA.VV. Actas XII Coloquio de Geografía Rural, León. Universidad de León, pp. 557-567.

GAMBAU, V. M. (2000): «Desarrollo rural en los espacios rurales europeos . Elementos de desigualdad». Revista Catalana de Sociología, $\mathrm{n}^{\circ}$ 14, 253-276.

GOERLICH, F. J., MAS, M. y DIRS, I. (2007): Actividad y Territorio. Un siglo de cambios. Bilbao: Fundación BBVA. Disponible en http://www.fbbva.es/TLFU/dat/DE_2007_ IVIE_actividad_y_territorio.pdf

GONZÁLEZ, M. J. y SAN MIGUEL, B. (2001): «El envejecimiento de la población española y sus consecuencias sociales». Alternativas: Cuadernos de Trabajo Social, $\mathrm{n}^{\circ}$ 9, 19-45. Disponible en http://dialnet.unirioja.es/servlet/articulo?codigo=2735935\&info=r esumen\&idioma $=$ SPA

GOZÁLVEZ, V. (2001): «Breve historial del desarrollo rural», en Martínez Puche, A. (ed.), El desarrollo rural/local integrado y el papel de los poderes locales. Nuevas consideraciones sectoriales a sus repercusiones en el territorio valenciano. Alicante. Universidad de Alicante. pp. 31-41.

KNOX, P. L. y COTTAM, M. B. (1981): «A Welfare approach to rural geography: contrasting perspectives on the quality of Highland life». Transactions, IBG, New Series, $\mathrm{n}^{\circ} 6$, 433-450.

MARTÍN, D., BRIGHAM, P. y RODERICK, R. (2000): «The (mis)representation of rural deprivation. Environment and Planning A», $\mathrm{n}^{\circ} 32,735-751$.

MARTÍNEZ ARNÁIZ, M. (2004): Patrimonio rural y ocio urbano. La banalización del recurso (en) AAVV. Actas del XII Coloquio de Geografía Rural. León. Universidad de León, pp. 607-615.

MAYA, V. (2004): «La realidad sociodemográfica de la mujer rural en Castilla y León», en AA.VV. Actas XII Coloquio de Geografía Rural, León. Universidad de León, pp. 285-298.

McLAUGLIN, B. P. (1986): «The rhetoric and the reality of rural deprivation». Journal of Rural Studies, ${ }^{\circ}$ 2, 291-307.

MOSELEY, S. D. (1979): Accesibility: The Rural Challenge. London. Methuen.

MURIE, A. y MUSTERD, S. (2004): «Social Exclusion and Opportunity Structures in European Cities and Neighbourhoods». Urban Studies, n ${ }^{\circ} 41,1441-1459$.

NOGUÉS, S. (2004): El futuro de los espacios rurales. Santander. Servicio de Publicaciones de la Universidad de Cantabria.

PHILIPS, D. y WILLIAMS, A. (1984): Rural Britain. A Social Geography. Oxford. Basil Blackwell.

PILLET, F. (2001): «Del agrarismo al desarrollo rural (aplicación a un territorio homogéneo)», en Pillet Capdepón, F. y Plaza Tabasco, J. (ed.), Lecciones de Desarrollo Rural. Ciudad Real. Universidad de Castilla-La Mancha, pp. 23-30.

ROOM, G. (1995): «Poverty in Europe: competing paradigms of analysis». Policy and Politics, $\mathrm{n}^{\mathrm{o}} 32(2), 103-113$. 
SHUCKSMITH, M. (2000): «Endogenous development, social capital and social inclusion: perspectives from LEADER in the UK». Sociologia Ruralis, n 40, 208-219.

SMITH, D. M. (1977): Human Geography: a welfare approach. New York. St. Martin's Press.

SMITH, D. M. (1979): Geographical perspectives on inequality. N. York. Barnes and Noble. VALENZUELA, M. (2008): «Administración territorial y políticas públicas para la promoción del turismo en las zonas rurales», en Cavaco, C. (ed.) Actas Do I Seminário Turismo E Planeamento Do Território: Turismo, Inovação E Desenvolvimento, pp. 209-235. 
